\title{
A framework for classifying opportunities to learn in Faculty Online Learning Communities: A preview with sample application
}

\author{
Alexandra C. Lau \\ Department of Physics, University of Colorado, 390 UCB, Boulder, CO 80309 \\ Adriana Corrales and Fred Goldberg \\ Center for Research in Mathematics and Science Education, \\ San Diego State University, 6475 Alvarado Road, Suite 206, San Diego, CA 92120 \\ Chandra Turpen \\ Department of Physics, University of Maryland, Toll Physics Building, College Park, MD 20742
}

\begin{abstract}
Faculty Online Learning Communities (FOLCs) are unique professional development environments built to support instructors as they adopt research-based teaching strategies and curricula. FOLC participants meet via a video conferencing platform to discuss their teaching challenges and to generate solutions. In order to capture the breadth and depth of learning that can occur by participating in a FOLC, and to identify connections between facilitation moves, discursive structures, and learning opportunities, we have developed a taxonomy to characterize the opportunities to learn (OTLs) in a FOLC meeting. In this paper we will preview the taxonomy, presenting its main components, and provide an overview of its development based on meetings from a FOLC centered around the Next Generation Physical Science and Everyday Thinking (NGPET) curriculum. Using an excerpt from a NGPET-FOLC meeting, we demonstrate how the taxonomy can be used as an analytical tool. We end with a discussion of the potential applications for this taxonomy.
\end{abstract}

2019 PERC Proceedings edited by Cao, Wolf, and Bennett; Peer-reviewed, doi.org/10.1119/perc.2019.pr.Lau Published by the American Association of Physics Teachers under a Creative Commons Attribution 4.0 license. Further distribution must maintain attribution to the article's authors, cover page, and DOI. 


\section{INTRODUCTION \& MOTIVATION}

Research-based instructional strategies (RBISs) and curricula for physics and astronomy education are abundant. Despite widespread knowledge of these innovations, their systemic and sustained adoption is lacking [1,2]. One of the proposed reasons for this lack of adoption is the general failure to support implementers of an innovation through the adoption process [24].

Faculty Online Learning Communities (FOLCs) are a promising solution to this problem [5-7]. Based on the design of in-person Faculty Learning Communities [8], FOLCs connect faculty members via periodic video conference calls with the goal of supporting their teaching development and implementation of RBISs. FOLCs can be centered around a particular curriculum, a particular teaching strategy, a specific course, or a certain population. The online nature of FOLCs affords the opportunity for faculty with specific interests to connect, even if they are geographically dispersed. A FOLC group is typically comprised of 6-10 members and is facilitated by two or three faculty members who are more experienced with the topic of the FOLC. During their online meetings, FOLC members troubleshoot issues with the course, curriculum, and/or pedagogical strategy they are trying to implement. These conversations are often rich with pedagogical ideas and advice [6, 9, 10].

Indeed, there is compelling evidence that FOLCs are supporting instructors in implementing teaching innovations and overcoming implementation challenges [7]. However, we don't expect FOLCs to be a silver bullet for supporting instructional change. We expect that subtle variations in the conversational norms of these groups are highly consequential for the learning opportunities that they offer. Thus, continued research is needed to assess the forms of learning possible in a FOLC. At the same time, there is a practical need to identify and develop best practices for structuring and running FOLCs. In order to satisfy these goals, we need a way to make sense of the complex, dynamic, and abundant social interaction which occurs during the hour-long FOLC meetings. Therefore, we are constructing a taxonomy for classifying the learning opportunities in a FOLC.

In this paper, we provide a preview of the taxonomy's overarching structure and components, its development process, and a sample application of the tool. Our purpose here is to give a concrete sense of how the tool can be used and the type of information it provides, rather than sharing a comprehensive presentation of the tool itself.

\section{TAXONOMY DEVELOPMENT}

\section{A. Opportunity to learn framework}

Our taxonomy is built to describe the types of learning opportunities afforded by different conversations within a FOLC meeting. We define an opportunity to learn (OTL) rather broadly, considering learning of both pedagogical and nonpedagogical knowledge. For the purposes of this taxonomy, we define pedagogical as attending to students' learning and/or the effect of teaching practice on students' learning. An OTL can range from discussing the logistics of a learning management system, to hearing about difficulties students face in a particular unit one will teach, to an opportunity to develop pedagogical concepts. Aligned with a sociocultural perspective on learning, we view OTLs as occurring through interactions on the social plane of a FOLC meeting [11-14]. The ideas developed through interactions on the social plane of the meeting can then be internalized by individual learners [12, 13]. When we talk about the OTLs which arise in a FOLC meeting, we are considering the learning possible for the collective FOLC group [11]. We do not attempt to make claims about individual, cognitive development.

The OTL framework is a particularly appropriate lens for analyzing FOLC meetings given our interest in understanding the social structure of a FOLC and how the space affords and constrains the group's learning about teaching. The OTL framework places the focus on the social organization of the FOLC space, rather than the individual learning of participants in the space. Thus, we have the potential to build more precise, linked claims between the structures and features of the learning environment and outcomes and impacts for the collective FOLC cohort.

\section{B. Development context}

The initial development of the taxonomy occurred in the context of our work with the Next Generation Physical Science and Everyday Thinking (NGPET) FOLCs. The NGPETFOLCs support five groups of instructors who are implementing the NGPET curriculum [15]. NGPET is a highly interactive, inquiry-based curriculum for future and in-service elementary teachers. The curriculum is also used in general education university science courses. NGPET is the current iteration of the Physics and Everyday Thinking (PET) [16], the Physical Science and Everyday Thinking (PSET) [17], and the Learning Physical Science (LEPS) curricula [18]. NGPET is aligned with the Next Generation Science Standards [19]. There are two versions of NGPET: one for lecturestyle courses and one for studio-style courses. The curriculum is comprised of five modules: Developing Models for Magnetism and Static Electricity; Interactions and Energy; Interactions and Forces; Waves, Sound, and Light; and Matter and Interactions. The modular design allows instructors to customize the curriculum to their needs, choosing which topics they will cover. The topics of NGPET-FOLC meetings are focused on implementation of the NGPET curriculum and challenges members are facing. 


\section{Taxonomy origins \& the taxonomy structure}

The taxonomy we preview in this paper is an adapted and expanded version of an existing framework for classifying opportunities to learn about teaching in the context of in-person teacher workgroups [11]. Horn, Garner, Kane, and Brasel constructed their taxonomy in the context of middle school mathematics teachers' workgroups, motivated by the need to describe how collegial conversations range in the nature and depth of support they provide for teachers' learning [11]. Horn and colleagues' framework for classifying OTLs defines six categories of workgroup meetings based on the pedagogical concepts developed, the degree of mobilization for future teaching work, and the nature of the discourse in the meeting. We used this framework as a starting point for analyzing NGPET-FOLC meetings.

Horn's taxonomy characterizes OTLs by considering both the content of a conversation as well as how participants engage in the conversation [11]. The taxonomy we preview below preserves this overall organization, but the outcome of applying that organization to FOLC meetings has resulted in a taxonomy which differs substantially from Horn's.

\section{Methodological process}

We reviewed a total of four NGPET-FOLC meetings, which occurred over the span of a year, from two NGPET-FOLC cohorts. We started the development of our taxonomy by applying Horn's framework to one NGPET-FOLC meeting. Through this process we identified a number of modifications that needed to be made for the tool to apply to our FOLC context. These changes included expanding Horn's definition of pedagogical concept development as well as adding a much finer level of detail to categorizing the nature of discourse (influenced by the work of Scott, Mortimer, and Aguiar [20]). Additionally, only about half of Horn's meeting categories applied to our FOLC meetings and those categories did not capture the full scope of meeting segment types we observe in the FOLCs. For example, Horn's categories do not account for the non-pedagogical discussions that occur in our FOLC, like when members are discussing the operation of the FOLC itself. We also found that Horn's taxonomy lacked a category for describing when our FOLC members give in-depth reports on a pedagogical issue they are facing without solutions being proposed.

Through an iterative cycle of coding and comparison of a total of four NGPET-FOLC meetings, we developed our definitions for how to describe the content of a conversation (encoded in our concept development codes and meeting segment category codes) and for how to describe the discursive nature of a conversation (encoded in our communicative approach codes). We purposefully chose the meetings used in developing the taxonomy to come for two cohorts with different norms in order to capture a range of what occurs in the NGPET-FOLCs. This work resulted in the first full version of

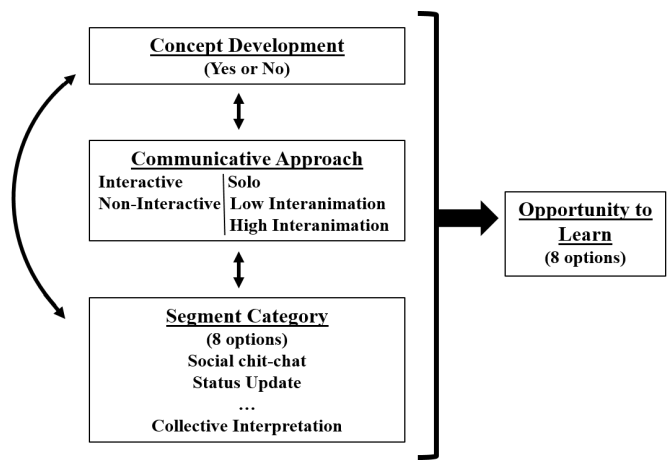

FIG. 1. Illustrating the major categories and sub-categories which make up the taxonomy, and the relationship between the constructs. The communicative approach (CA), concept development (CD), and segment category (SC) are interconnected, mutually informing each other. Together, the CA, CD, and SC of a meeting excerpt (all specified by the relevant sub-codes) suggest a particular OTL provided by the excerpt.

the taxonomy for classifying OTLs in FOLC meetings.

\section{TAXONOMY PREVIEW}

The major elements and organization of the current version of our taxonomy are shown in Fig. 1. Here we summarize the components of the tool and present an example of the tool in use. Our main goal is to provide a snapshot of what this tool can be used for, rather than providing a full presentation of the tool itself. We highlight the elements of the taxonomy related to the sample analysis we share. In a forthcoming paper we will present examples of all the taxonomy elements, more detailed descriptions of the links between different taxonomy components, and a full set of coding rules for applying the tool.

To apply the taxonomy, we first divide a meeting into segments based on shifts in conversational purpose [21]. Then for each segment, we consider the nature of the discourse (the Communicative Approach) along two dimensions (these dimensions are from [20]). We characterize who is talking by labeling a segment as interactive or non-interactive. We also characterize how ideas are discussed; if only one perspective on an idea is presented the segment is labeled as "solo," while if multiple perspectives are presented the segment is labeled as "dialogic." Dialogic discourse can further be classified as incorporating either "low-interanimation" of ideas, where ideas are simply made available to the social plane of the conversation, or "high interanimation" of ideas, where ideas are developed, compared, and worked on [20].

For each segment, we next consider the content of what was said. We determine whether there was a pedagogical concept developed. Concept development occurs when conversation, "bring $[\mathrm{s}]$ the general and the particular together-by surfacing the formal dimensions of lived concepts or illustrating lived examples of formal concepts" [11]. We look for linkage be- 
tween lived classroom experiences and formal principles on teaching and learning.

We also apply a segment category to the segment to further describe its content. We have determined eight meeting segment categories which seem sufficient to describe the range of conversations that occur in the NGPET-FOLC. Some examples of these categories are "Social Chit-Chat" about members" life outside of work, "Status Update" of how one's class is going, "Generating detailed descriptions and explanations for a pedagogical problem," and "Collective Interpretation" of a pedagogical issue which results in a pedagogical concept being developed in the group.

For each meeting segment category (in conjunction with the Communicative Approach and Concept Development coding), we have defined an associated OTL. Taking the "Collective Interpretation" category as an example, we say that in those segments there is the opportunity to learn robust (research/theorybased) ideas about teaching and learning that are instantiated in specific examples of classroom practice. These ideas may be accompanied by envisioned possibilities of how to apply the ideas in future classes. Note too, the concept of an OTL generalizes beyond pedagogical learning. For example, the "Social Chit-Chat" meeting category provides an opportunity to learn about fellow FOLC members and form relationships.

\section{SAMPLE ANALYSIS HIGHLIGHTING COMPONENTS OF THE TAXONOMY}

Having previewed the structure and some critical elements of the taxonomy, we will now present an example of the taxonomy in use. This will illustrate portions of the taxonomy and its efficacy for analyzing FOLC meetings. The example we present comes from a NGPET-FOLC meeting that took place about midway through the first full year of the FOLC and lasted about 60 minutes; the discussion in Table I is an excerpt from that meeting. The meeting started with one of the cohort leaders suggesting that everyone share something from their class. Carter and Courtney are cohort leaders; Wallace is a cohort member.

In the excerpted segment (Table I), the group discusses the magnetism unit of the NGPET curriculum. This unit consists of a series of activities that lead students to develop the model of magnetism; this process extends over multiple class periods. Wallace shares that during the unit some of his students google how magnetism works and read about domains. The students then bring that idea into class (without basing it on any evidence developed during class) and he worries this undermines the learning process. Courtney points out that even if students use that term (domains) they do not understand what it means, and Wallace agrees. Carter adds that that is evidence of the students' epistemology, that they think knowing a word is the same as understanding what it means. He then gives an example from his class where a student thinks he understands something just because he knows the words, but cannot really explain it in a way consistent with the course goals.
When coding this segment, we consider what is talked about and how it is discussed, with an overall eye towards the opportunities to learn. How would we code the communicative approach of this excerpt? We say that the segment is interactive because multiple people make substantive contributions (e.g. Wallace in T1, Courtney in T2, and Carter in T6). We further categorize this as a dialogic conversation with high interanimation. This means multiple perspectives on an idea are presented (dialogic) and these ideas are compared and developed (high-interanimation). In the segment, participants consider multiple perspectives on the issue of students googling how magnetism works and develop an idea of what it means to understand something.

How would we classify what is talked about? We say that there is concept development in this segment, which means lived concepts (LCs) are linked to formal concepts (FCs). In the transcript (Table I), we have highlighted the LCs (in orange) and the FCs (in blue) that are critical to our decision that a concept was developed. Wallace shares an LC (based on his experience in the classroom) that students google information about how magnetism works and they then start talking about domains in class, which he thinks skews the learning process. Courtney responds with her LC that students don't really understand the information they google and they can't explain the term "domain" to the class when they bring it up. Carter connects these LCs to the formal concepts that the students' problems are evidence of their epistemology, that they don't have a sophisticated view of what it means to understand something in science and that they tend to equate terminology with understanding. Carter then connects this FC to an LC involving a student in his class who could not understand why he was not able to explain something in a way that satisfied the instructor. With these connections between LCs and FCs, the concept that students tend not to have a sophisticated understanding of what it means to understand something in science, that they tend to equate terminology with understanding, is developed. The conversation moves from, "My students googling things is potentially problematic for the learning process constructed by the curriculum," to a discussion of a deeper issue which underlies the googling behavior: students' epistemology of learning science.

We classify this segment overall as Collective Interpretation. The group collectively addresses a pedagogical issue and develops a pedagogical concept (Collective Interpretation). This conversation offers meeting attendees the opportunity to expand their pedagogical understanding as they engage with the issue of students googling information outside of class.

\section{DISCUSSION \& CONCLUSION}

The taxonomy allows us to dissect complex interactions and then distill out the overall OTL provided by a segment of a FOLC meeting. When the taxonomy is applied to each segment of a full, hour-long meeting we are left with a short list of the OTLs provided in that meeting. Depending on 
TABLE I. Transcript of an excerpt of a NGPET-FOLC meeting. All names are pseudonyms. The lived concepts (in orange) and formal concepts (in blue) that are critical to our claim that concepts were developed are marked.

\begin{tabular}{|c|c|c|}
\hline Turn & Speaker & Transcript \\
\hline $\mathrm{T} 1$ & Wallace & $\begin{array}{l}\text { The other issue I have, which is ... I think this mainly arises because we meet only twice a week for such a short time, } \\
\text { so the module gets drawn out over a few weeks, is some students go away and google how magnetism works, and so } \\
\text { suddenly they'll be talking about domains. Okay, so this is kind of skewing the process. }\end{array}$ \\
\hline $\mathrm{T} 2$ & Courtney & $\begin{array}{l}\text { Yeah, but I've found that in my experience anyway, if they go away and they come back with domains that they usually } \\
\text { don't have any idea how they actually work. }\end{array}$ \\
\hline $\mathrm{T} 3$ & Wallace & No, yeah, that's true. \\
\hline $\mathrm{T} 4$ & Courtney & $\begin{array}{l}\text { They try to use domains to explain whatever, and they can't, and so the rest of the class is like, "Well, never mind that. } \\
\text { We'll just forget ..." }\end{array}$ \\
\hline T5 & Wallace & $\begin{array}{l}\text { I think that is true. They google the answer, but they're not really quite understanding what's going on still. I'm not too } \\
\text { worried about that. It was just funny when they suddenly start pulling out these words. }\end{array}$ \\
\hline T6 & Carter & $\begin{array}{l}\text { Kind of seems like it's evidence about the students' epistemology, like I feel like they don't have very sophisticated } \\
\text { views about what it means to understand something. }\end{array}$ \\
\hline $\mathrm{T} 7$ & Courtney & Oh, they don't. \\
\hline $\mathrm{T} 8$ & Carter & $\begin{array}{l}\text { Because science context, what it means to understand something, and so for them understanding means like knowing the } \\
\text { term or being familiar with the term when we're trying to give them an experience that's so much different view of what } \\
\text { it means to understand something, and there's a tension there. }\end{array}$ \\
\hline T9 & Courtney & Yeah, they want to memorize. "I must memorize." \\
\hline $\mathrm{T} 10$ & Carter & $\begin{array}{l}\text { I had a student after the quiz, he was in my office complaining, different student than the other one that I mentioned } \\
\text { earlier, he's going about how he understands everything in this class, because after all this class is like baby physics, and } \\
\text { he learned it all in high school, but he just can't explain it the way that I want him to. He went on and on and on and on. } \\
\text { I tried to provide some, "Have you thought about maybe writing an outline of the key bullet points that you wanna hit in } \\
\text { your explanation, and only then start ..." }\end{array}$ \\
\hline T11 & Carter & $\begin{array}{l}\text { I just tried everything I could to get him to reflect on maybe I don't fully understand it. My struggles are evidence that I } \\
\text { don't fully understand it. Every time I tried to hand it back to him, he just kept handing it back to me. Like, "No, this is } \\
\text { so easy, and I just ... yeah, I can't explain it the way you want." Oh God, just leave. }\end{array}$ \\
\hline T12 & Courtney & Right. \\
\hline
\end{tabular}

the grain size of interest, this taxonomy can be useful for conducting micro analyses (like the one presented in the above section) or for developing broader claims (e.g. coding whole meetings based on their dominant segment type and looking for patterns over time).

Regardless of the scale of analysis, we envision a number of possibilities for how this tool can be used. One option is to use the taxonomy to study the change in a FOLC cohort's conversations over time. For example, we can see if a FOLC cohort whose early meetings are dominated by status updates and limited conversational interaction later has meetings which are characterized by lots of interaction and collective concept development. A second application of the tool is to help identify connections between facilitation moves, discursive structures, and learning opportunities. If a cohort's meetings do change over time, the taxonomy can help us develop strong candidate claims as to why the change may have occurred. As we apply this taxonomy across a larger data set, we anticipate being able to build accounts of how conversational norms matter for the OTLs that FOLCs offer. A third application of the tool is to use it to compare the nature of different cohorts' meetings. Our experience with the NGPET-FOLC groups indicates that the patterns of interaction and content discussed during meetings can vary widely between cohorts. For example, we expect that some groups may be more oriented towards in-the-moment problem solving while other cohorts concern themselves with long discussions of formal teaching and learning concepts.

The taxonomy is a flexible tool that can be used to characterize FOLC cohorts, compare them, and provide information on how they are functioning. All of this is essential as we continue to develop best practices for supporting faculty as they are implementing changes in their teaching.

\section{ACKNOWLEDGMENTS}

We thank the faculty members of the NGPET-FOLC for their commitment to teaching and learning and their participation in this research study. Additionally, we thank Ed Price and Melissa Dancy for their feedback as part of the NGPETFOLC research team. This work is supported by NSF grant 1626496. 
[1] C. Henderson, M. Dancy, and M. Niewiadomska-Bugaj, Use of research-based instructional strategies in introductory physics: Where do faculty leave the innovation-decision process?, Phys. Rev. ST Phys. Educ. Res. 8, 020104 (2012).

[2] J. E. Froyd, C. Henderson, R. S. Cole, D. Friedrichsen, R. Khatri, and C. Stanford, From dissemination to propagation: A new paradigm for education developers, Change: The Magazine of Higher Learning 49, 35 (2017).

[3] E. M. Rogers, Diffusion of innovations, 5th ed. (Free Press, New York, 2003).

[4] A. Rundquist, J. Corbo, S. Chasteen, M. S. Martinuk, C. Henderson, and M. Dancy, Faculty online learning communities to support physics teaching, in Physics Education Research Conference Proceedings 2015, PER Conference (College Park, MD, 2015) pp. 279-282.

[5] M. Dancy, A. Lau, J. Corbo, C. Henderson, and A. Rundquist, Participants' perceptions of the faculty online learning community (folc) experience, in Physics Education Research Conference Proceedings 2017, PER Conference (Cincinnati, OH, 2017) pp. 100-103.

[6] C. Turpen, F. Goldberg, A. Corrales, and E. Price, Confusion and representational practices as factors that sustain rich pedagogical discussions within faculty online learning communities, in Physics Education Research Conference Proceedings 2018, PER Conference (Washington, DC, 2018).

[7] M. Dancy, A. C. Lau, A. Rundquist, and C. Henderson, A model for sustained teaching transformation: Faculty online learning communities (2019), (Unpublished).

[8] M. D. Cox, Introduction to faculty learning communities, New Directions for Teaching and Learning 97, 5 (2004).

[9] A. Corrales, F. Goldberg, C. Turpen, and E. Price, Conversational norms in faculty communities enable and constrain opportunities to learn, in Physics Education Research Conference Proceedings 2018, PER Conference (Washington, DC, 2018).

[10] A. C. Lau, M. H. Dancy, C. Henderson, and A. Rundquist, Describing and facilitating productive teaching talk in a faculty online learning community, in Physics Education Research Con- ference Proceedings 2018, PER Conference (Washington, DC, 2018).

[11] I. S. Horn, B. Garner, B. D. Kane, and J. Brasel, A taxonomy of instructional learning opportunities in teachers' workgroup conversations, J. of Teacher Educ. 68, 41 (2017).

[12] L. S. Vygotsky, Mind in society: the development of higher psychological processes (Harvard University Press, Cambridge, 1978).

[13] L. S. Vygotsky, Thought and language, translation newly rev. and edited ed., edited by A. Kozulin (MIT Press, Cambridge, MA, 1986).

[14] H. Daniels, Vygotsky and research (Routledge, New York, 2008).

[15] F. Goldberg, S. Robinson, E. Price, D. Harlow, J. Andrew, and M. McKean, Next generation physical science and everday thinking, http://activatelearning.com/next-generation-pet/ (no date), Accessed April 16, 2019.

[16] F. Goldberg, S. Robinson, and V. Otero, Physics and everyday thinking, https://activatelearning.com/physics-and-everydaythinking/ (2006).

[17] F. Goldberg, R. Kruse, S. Robinson, V. Otero, and N. Thompson, Physical science and everyday thinking, https://activatelearning.com/physical-science-and-everydaythinking/ (no date), Accessed April 16, 2019.

[18] F. Goldberg, S. Robinson, R. Kruse, D. B. Harlow, and M. McKean, Learning physical science, http://activatelearning.com/learning-physical-science/ (no date), Accessed July 2, 2019.

[19] Next generation science standards, https://www.nextgenscience.org/ (no date), Accessed April 16, 2019.

[20] P. H. Scott, E. F. Mortimer, and O. G. Aguiar, The tension between authoritative and dialogic discourse: A fundamental characteristic of meaning making interactions in high school science lessons, Science Educ. 90, 605 (2006).

[21] E. A. Schegloff, Sequence organization in interaction: A primer in conversation analysis, Vol. 1 (Cambridge University Press, New York, 2007). 